\title{
O PRINCÍPIO DE BREVIDADE E A ATUAÇÃO PROFISSIONAL FRENTE AO TEMPO DE PRIVAÇÃO DE LIBERDADE
}

\section{Cristiano Rodineli de Almeida ${ }^{1}$ Sidelmar Alves da Silva Kunz ${ }^{2}$}

\begin{abstract}
Resumo: este artigo é resultado de pesquisa desenvolvida com socioeducadores de um Centro de execução de Medida de Internação localizado na cidade de São Paulo. Investigou-se a compreensão desses profissionais acerca da efetividade do Princípio de brevidade na condução dos casos dos adolescentes internados na instituição. Utilizou-se como método a pesquisa qualitativa, fazendo uso de questionário semi-estruturado e de diálogos estabelecidos com os socioeducadores. Como parte dos resultados, constatouse que o tempo da Medida Socioeducativa de Internação é considerado uma importante variável e utilizada como método de intervenção por supostamente provocar mudanças no adolescente a despeito das demais intervenções técnicas e pedagógicas.
\end{abstract}

Palavras-chave: Socioeducação - Princípio de brevidade - Adolescente.

\section{THE BREVITY PRINCIPLE AND PROFESSIONAL ACTING FRONT THE TIME OF DEPRIVATION OF LIBERTY}

Abstract: this article is a result of research developed with socioeducators of a Center for the Execution of Internment Measure located in the city of São Paulo. It was

\footnotetext{
1 Mestrado em Educação e Saúde na Infância e na Adolescência pela Universidade Federal de São Paulo (UNIFESP), Especialista em Psicopatologia e Saúde Pública pela Universidade de São Paulo (USP) e em Políticas Públicas e Socioeducação pela Escola Nacional de Socioeducação da Universidade de Brasília (ENS/UnB). Atua como psicólogo na Fundação CASA, atendendo adolescentes privados de liberdade, além de atuar também como psicólogo clínico de orientação psicanalítica. É membro do corpo editorial da Revista Pathos - Rev. Brasileira de Práticas Públicas e Psicopatologia. E-mail: cris.rondinelli@gmail.com

2 Doutorando em Educação pela Faculdade de Educação da Universidade de Brasília (UnB). Atua como Pesquisador do Instituto Nacional de Estudos e Pesquisas Educacionais Anísio Teixeira (INEP) e integra o quadro docente do Curspo de Especialização em Ensino Interdisciplinar em Infância e Direitos Humanos da Universidade Federal de Goiás (UFG) e orienta monografias no Curso de Especialização em Políticas Públicas e Socioeducação da Escola Nacional de Socioeducação (ENS/UnB). E-mail: ens.sidel@gmail.com
} 
investigated the understanding of these professionals about the effectiveness of the Principle of brevity in the conduct of the cases of adolescents deprived of liberty in the institution. Qualitative research was used as a method, using a semi-structured questionnaire and dialogues established with the socioeducators. As part of the results, it was verified that the time of the Socio-educational Measure of Internment is considered an important variable and used as intervention method for supposedly provoking changes in the adolescent despite other technical and pedagogical interventions.

Keywords: Socioeducation - Principle of brevity - Adolescent.

\section{EL PRINCIPIO DE BREVEDAD Y LA ACTUACIÓN PROFESIONAL FRENTE EL TIEMPO DE PRIVACIÓN DE LIBERTAD}

Resumen: este artículo es el resultado de una investigación desarrollada con socioeducadores de un Centro de ejecución de Medida de Internamiento ubicado en la ciudad de São Paulo. Se investigó la comprensión de estos profesionales acerca de la efectividad del Principio de brevedad en la conducción de los casos de los adolescentes internados en la institución. Se utilizó como método la investigación cualitativa, haciendo uso de cuestionario semiestructurado y de diálogos establecidos con los socioeducadores. Como parte de los resultados, se constató que el tiempo de la Medida Socioeducativa de Internación es considerado una importante variable y utilizada como método de intervención por supuestamente provocar cambios en el adolescente a despecho de las demás intervenciones técnicas y enseñanza.

Palabras clave: Socioeducación - Principio de brevedad - Adolescente.

\section{Introdução}

No Brasil, o número de Medidas Socioeducativas de Internação determinadas aos adolescentes em conflito com lei tem registrado algumas alterações na última década. Houve aumento de cerca de $20 \%$ das internações entre os anos de 2009 e 2012, “[...] configurando uma taxa de internação de 100 adolescentes por 100 mil habitantes" (ONU, 2015, p.08).

Entre 2011 e 2016 passou de 13.362 para 18.567, aumento de 38\%. No estado de São Paulo, aponta-se diminuição de 3,5\% no número de adolescentes atendidos em seus programas socioeducativos ${ }^{3}$, de 2015 a 2016(BRASIL, 2018). Esse declínio a

\footnotetext{
3 Conjunto das Medidas de Internação, Internação Provisória, Internação Sanção, Atendimento Inicial e
} Semiliberdade. 
partir do ano de 2015 também é registrado na variação histórica do Boletim Estatístico da Fundação CASA, demonstrada no Gráfico 1:

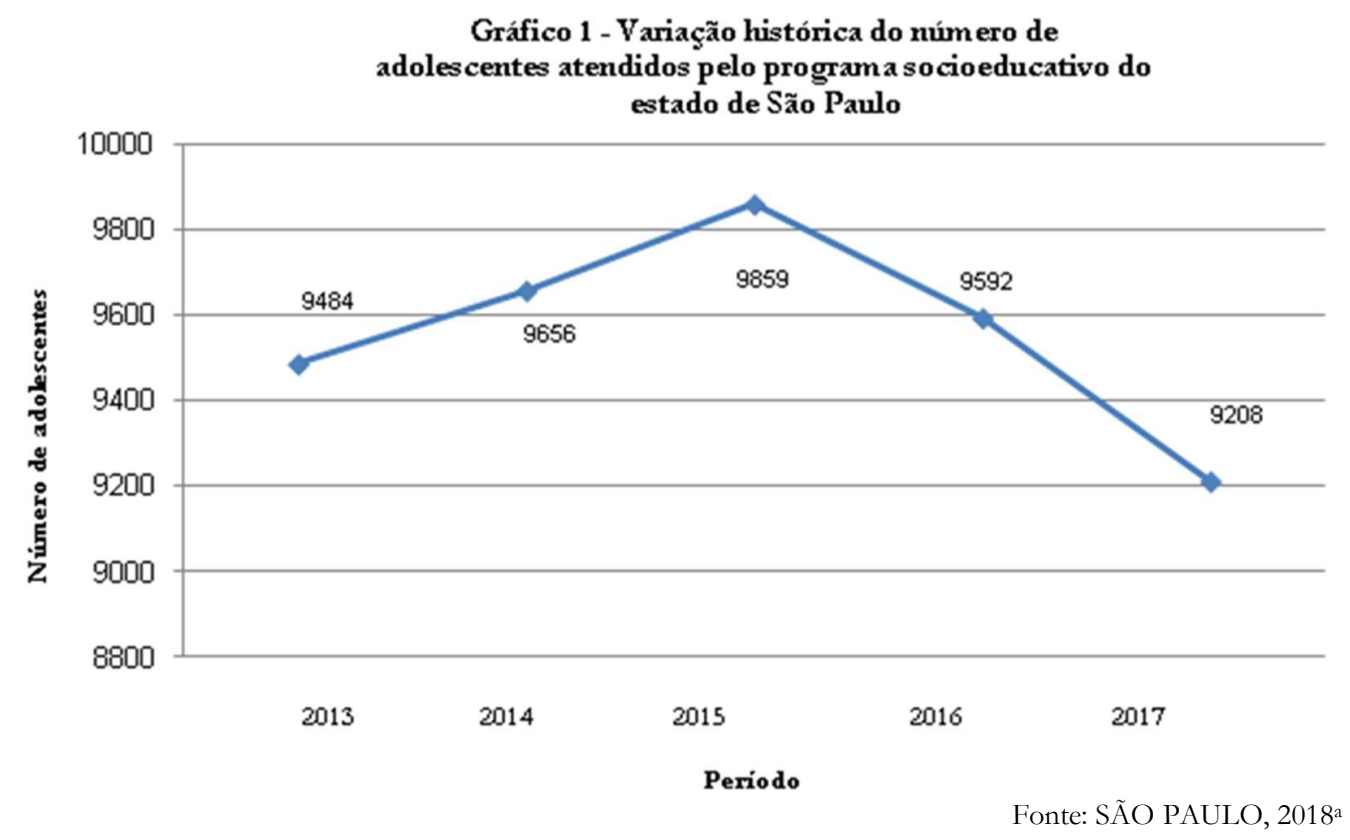

Nota-se que São Paulo tem registrado diminuição no número de internações, mas ainda desponta como a unidade federativa com maior número de adolescentes encarcerados, apresentando em 2016 um total de 9572 adolescentes em seus programas, seguido por Rio de Janeiro (2293) e Minas Gerais (1964) (BRASIL, 2018). Conforme dados atuais ${ }^{4}$, a Fundação CASA atende 8689 adolescentes, demonstrando uma queda 9,2\% em relação aos números de 2016 (SÃo PAULO, 2018a).

A privação de liberdade é a Medida mais severa de todas conforme preconizado na legislação brasileira e tem sido utilizada como referência no combate ao fenômeno da violência urbana, atribuindo ao adolescente em conflito com a lei à responsabilidade dessa questão pungente em nossa sociedade e considerando seu encarceramento como a solução mais adequada (BRASIL, 2012b).

A execução da Medida Socioeducativa de Internação ocorre por tempo indeterminado, não havendo fixação de um prazo específico para que o adolescente

${ }^{4}$ Junho/2018. 
fique recluso, com exceção de dois limitadores: duração de no máximo três anos ou até que o adolescente complete 21 anos de idade (BRASIL, 2012a). Salvo essas duas situações, são os socioeducadores que percebem o momento que a Medida findou, sugerindo possíveis alterações da Medida de internação ao judiciário.

Conforme a Lei do SINASE, as Medidas Socioeducativas têm por objetivo a desaprovação da conduta ilícita, a responsabilização do ato infracional, a integração social do adolescente e seu acesso aos direitos individuais. Portanto, o Plano Individual de Atendimento (PIA) ${ }^{5}$, ao passo que contemple esses pontos, apresentase como elemento norteador para o tempo da Medida: a evolução e conclusão de suas metas podem sinalizar que a Medida atingiu seus objetivos.

Dado o caráter punitivo da Medida de internação, o aspecto cronológico deve ser considerado. Nesse sentido, o Princípio de brevidade se apresenta de extrema relevância, pois compreende o adolescente como sujeito em condição peculiar do desenvolvimento e percebe a privação de liberdade como locus de possível sofrimento. Assim, as intervenções devem ser ministradas no menor tempo possível sob risco de perderem o caráter socioeducativo.

Compreender a utilização do Princípio de brevidade na condução dos trabalhos voltados ao adolescente privado de liberdade é de extrema importância, pois evidencia a necessidade dos aspectos socioeducativos definidos na legislação em detrimento a vieses punitivos que uma Medida demasiadamente longa possa causar ao adolescente. Em tempos de endurecimento das Medidas, corre-se o risco de manter o adolescente privado de liberdade para além do necessário, o que se apresenta como uma violação de direitos a esse público e coloca a Medida de internação em posição análoga ao modelo carcerário (BRASIL, 2012b).

Desse modo, esta pesquisa buscou investigar se as práticas profissionais dos socioeducadores encontram-se tangenciadas pelo Princípio de brevidade. Para isso, aplicamos questionário e estabelecemos diálogos com 20 socioeducadores de um Centro de Internação da cidade de São Paulo. Os resultados foram analisados sob a luz de norteadores jurídicos e de referenciais teóricos, de modo a discutir, para além

\footnotetext{
5 Documento elaborado pela Equipe de Referência do Centro de Internação em conjunto com o adolescente e sua família. Nele são definidas metas a serem alcançadas pelo adolescente e sua família, conforme artigo 53 da Lei do SINASE. Essa elaboração conjunta possibilita, para além da participação do adolescente e de sua família na condução da Medida, a oportunidade da subjetividade do adolescente ser privilegiada nesse contexto (MELGAÇO \& ALMEIDA, 2016).
} 
do campo conceitual, a aplicabilidade desse Princípio nas práticas desses profissionais.

\section{Perspectiva Metodológica da Pesquisa}

O desenvolvimento desta pesquisa tem como método a abordagem qualitativa, bem como a quantificação de alguns dados, realizados a partir da aplicação de questionário com perguntas abertas e fechadas aos socioeducadores acerca de suas percepções sobre o Princípio de brevidade.

Com o repertório metodológico construído, partimos para a etapa da prétestagem. Tratou-se de um momento em que o questionário foi colocado a apreciação de especialistas da área da socioeducação para validação e pertinência das questões abordadas na ferramenta. Esse momento contribuiu para o aprimoramento e organização do questionário.

Em paralelo com esse procedimento, solicitamos autorização para a pesquisa junto à Escola de Formação e Capacitação Profissional da Fundação CASA. Após essa aprovação, realizamos reunião com o Diretor e Encarregado técnico do Centro de internação pretendido, ocasião que apresentamos a pesquisa e a metodologia a ser utilizada. Foi-nos oferecido a possibilidade de acessar diretamente os profissionais e realizar os convites. Essa liberdade permitiu que, para além da apresentação da pesquisa e realização dos convites, estabelecesse diálogos com esses sujeitos.

O diálogo estendeu-se para além desse momento inicial, na ocasião de devolução dos questionários. Embora o questionário apresente em sua maioria questões fechadas, abrimos a possibilidade para que cada profissional entrevistado falasse sobre os conteúdos mobilizados a partir de cada pergunta, de modo a oferecer escuta às demandas que emergiam nesse diálogo e estavam relacionadas, invariavelmente, a impasses vividos em suas práticas de trabalho. Consideramos o diálogo estabelecido com os socioeducadores como também uma ferramenta metodológica de coleta de dados.

\subsection{Caracterizações do campo e dos sujeitos de pesquisa}

Os sujeitos participantes desta pesquisa compõem o quadro profissional de um Centro de Internação localizado na cidade de São Paulo. Por questões éticas firmadas com os sujeitos de pesquisa, além do sigilo de suas identidades, foram preservados também o nome do Centro de Internação pesquisado. É possível revelar que se trata 
de um Centro com cerca de 50 adolescentes custodiados com base no Artigo 122 do ECA.

Nossa investigação contemplou profissionais que participassem diretamente das discussões de caso e da elaboração do Plano Individual de Atendimento dos adolescentes, como os socioeducadores das áreas de segurança, psicossocial, saúde e pedagógica. Esses diversos profissionais se organizam em equipes multidisciplinares, chamadas de Equipes de Referência, as quais se apresentam como referência na condução dos trabalhos voltados a determinados grupos de adolescentes.

As Equipes de Referência têm basicamente a função de discutir elementos de cada caso, auxiliando os adolescentes na elaboração e monitoramento das metas do PIA, cabendo à equipe a aplicação do Princípio de brevidade em suas práticas de trabalho. As reuniões ocorrem com periodicidade semanal ou em frequência modulada por outras exigências, como ocorrências entre adolescentes, a necessidade de encaminhamentos ou de respostas demandadas pelo judiciário.

Na próxima subseção discutiremos conceitos entendidos como centrais para esta pesquisa, tal como privação de liberdade, Princípio de brevidade, sofrimento psíquico e relações trabalho, momento que trataremos mais distintamente a atuação dos profissionais no Centro de atendimento. Discutiremos os referenciais teóricos à luz dos documentos legislativos nacionais e internacionais, de modo subsidiar as discussões no capítulo da análise dos dados.

\subsection{Princípio de brevidade e a ideia de saturação da medida}

(...) a Medida tornou-se uma escada rolante, onde o adolescente tem momentos altos e baixos. Deixa de se pensar na evolução do adolescente e passou-se a mirar no castigo da internação. (ENTREVISTADO Z.)

O Princípio de brevidade preconizado pelo Estatuto da Criança e do Adolescente(ECA) e pelo SINASE é considerado o "princípio cronológico" da Medida Socioeducativa, pois defende a ideia de que as intervenções socioeducativas devem ser aplicadas no menor tempo possível, levando em consideração as intensas e rápidas mudanças ocorridas na fase da adolescência.

Esse princípio compreende que o adolescente se encontra em fase peculiar de constantes mudanças em seu corpo, intelecto e psiquismo, e que elas podem ser 
impactadas em razão do viés punitivo de um ambiente tão insalubre como a privação de liberdade, por produzir "mínimos efeitos positivos", pois o objetivo primordial da socioeducação é a ressocialização e não o encarceramento (SARAIVA, 2014.p. 47).

Espera-se que o adolescente internado conquiste as metas estipuladas em seu PIA, no entanto, o tempo de internação pode se apresentar como uma variável que em certo momento impactará nos avanços ou na manutenção dessas conquistas, resultando, inclusive, em retrocessos. 0 alongamento da Medida pode se apresentar, no campo legal, como uma violação de direitos e, no campo psíquico, como uma violência.

Oliveira (2014) aponta que o adolescente privado de liberdade pode ser avaliado de maneira cindida da realidade que habita. 0 encarceramento é desconsiderado como uma variável que pode impactar negativamente na evolução da Medida, havendo em prol do "processo ressocializador" uma insistência em manter o adolescente privado independente de sua relação com a Medida, dando-nos a impressão que os fins justificam os meios (OLIVEIRA, 2014).

0 alongamento da privação de liberdade evidencia como o viés punitivo tangencia a todo o momento a Medida. Essa reflexão nos remete ao conceito de mortificação do $e u$, definido por Goffman (1974) como um movimento institucional que busca condicionar a subjetividade do sujeito em prol de um suposto controle, como é o caso da obrigação de executar rotina diária alheia a ele ou que não se identifica com ela.

Além disso, há outros indícios do processo de mortificação do eu, como a "violação da reserva de informação do eu" (GOFFMAN, 1974, p.31), que diz respeito à perda da confidencialidade das informações sobre a história de vida do sujeito, agora compartilhadas entre diversas pessoas (judiciário, equipes técnicas e de referência); submissão à "autoridade difusa"(GOFFMAN, 1974, p.126), que no caso dos adolescentes em cumprimento de Medida Socioeducativa de internação estão submetidos à autoridade judiciária e a todos que a exercem no Centro de atendimento; e a posição humilhante do corpo e da palavra, facilmente identificado em alguns Centros de Internação pelas cabeças baixas, mãos para trás ou pelos “sim senhor, sim senhora" ditos pelos adolescentes ao se referir a qualquer socioeducador.

Yokomisso (2007) contribui com essa discussão ao apresentar a ideia de "represamento pulsional": 
A renúncia pulsional - embora garanta o advento do grupo - sufoca seus membros e encaminha-os a experiência intolerável. A Fundação, assim, passa a ser o alvo de ataques a fim de que se preserve a ilusão do grupo e seus excessos na função instituinte (YOKOMISO, 2007, p.127)

Desse modo, é possível que a violência praticada por adolescentes dentro do contexto privativo de liberdade também possa ser considerada parte sintomática advinda do encarceramento desses sujeitos. Vicentin (2016) aponta outros possíveis sintomas da privação de liberdade, vividos pelos adolescentes como sofrimentos demonstrados, entre outras formas, por "sinais de depressão ou ideação suicida, [ou] na demanda dos adolescentes por medicação para dormir ou para se acalmar" (VICENTIN, 2016, p. 25, grifo nosso).

Trata-se, portanto, de um movimento de fuga do contexto aversivo da internação e que coloca as metas do PIA em segundo plano. Zapata (2010) questiona a possibilidade de sustentação pedagógica de Medidas que têm seus prazos estendidos, justamente pelo caráter coercitivo com que elas são percebidas pelos adolescentes:

[...] acompanhando a execução das medidas socioeducativas, trouxe-lhe a percepção de que, o que se observa constantemente nas unidades de internação da Capital, não parece ser um trabalho voltado de forma predominante à socioeducação, mas à contenção pela contenção (ZAPATA, 2010, p.14)

Desse modo, ressaltamos a importância de se observar a brevidade para não se correr o risco de se reproduzir elementos do sistema carcerário dispensados aos adultos, o qual não se configura como modelo de processo ressocializador.

Ao pensarmos na observância do Princípio de brevidade na execução da Medida, remetemo-nos a “[...] eficiência das equipes técnicas dos programas de atendimento, quando da elaboração dos Planos Individuais de Atendimento e dos relatórios de reavaliação periódica e do cumprimento das metas". (MINAS GERAIS, 2014, p.56).

Falamos aqui das possibilidades de encontros significativos entre socioeducadores e adolescentes que proporcionem a construção de projetos de trabalho voltados às demandas dos jovens e que possam ser executadas dentro do menor tempo possível, no que concerne ao contexto restritivo de liberdade. Os projetos estipulados no Plano Individual de Atendimento não se esgotam na Medida de Internação, são metas que extrapolam os muros, grades e portas cerradas. São metas para a vida. 


\subsection{Socioeducador e sua relação com a medida de internação}

Socioeducador é identificado como o profissional responsável pelo desenvolvimento de ações relacionadas à educação social, voltadas a sujeitos atingidos pelas mazelas oriundas das desigualdades sociais. No caso dos adolescentes e jovens privados de liberdade, o socioeducador se debruça na elaboração de estratégias que possibilitem o resgate da cidadania e sua emancipação como sujeito de direitos, ações que possam se mostrar significativas na mudança da trajetória ilícita e situações de riscos vivenciadas até então (LIMA, et al. 2018).

O papel do socioeducador nos Centros de Internação, o que a priori nos remete a um lugar de potência, é tangenciado por diversos conflitos que dizem respeito não somente as tensões vividas com os adolescentes e a instituição, mas também com sua própria identificação enquanto profissional implicado no desenvolvimento humano e na garantia dos direitos fundamentais dos adolescentes (HERCULANO; GONÇALVES, 2011).

Para além desses conflitos, a articulação entre os profissionais e como se estabelecem em suas funções podem cindir o desenvolvimento de um trabalho integrado e conciso entre a equipe. No Centro de internação pesquisado duas posições de trabalho se destacam: de um lado, aqueles que lidam diretamente com os adolescentes, passando até 12 horas nessa relação, e por isso nutrindo um ponto de vista mais pragmático acerca desses sujeitos, e, do outro lado, profissionais que ocupam o lugar de um suposto saber ao deterem informações privilegiadas e confidenciais sobre o processo e a vida do adolescente.

Essas duas posições podem assumir lugares de complementação dos trabalhos ou favorecer um enrijecimento das práticas, isolando-as em espécies de guetos profissionais e dificultando a possibilidade de diálogos que possam contribuir no desenvolvimento dos casos. Não somente as divisões de tarefas na socioeducação podem cindir os grupos. No interior desses próprios guetos é possível que haja discordâncias em relação aos métodos de trabalho adotados por cada socioeducador:

Embora sejam desconsideradas, muitas vezes, em nome da harmonia e do profissionalismo, o grupo que acredita na socioeducação, critica o preconceito demonstrado pelo grupo que vê mais eficiência nas medidas repressivas do que na socioeducação (...) (HERCULANO; GONÇALVES, 2011. p. 96).

Entre os profissionais que passam maior tempo em atividades com os adolescentes destacam-se os agentes de apoio socioeducativo. Ocupam lugares 
estratégicos para o andamento das atividades e a manutenção da organização do Centro, com vistas a: “Garantir as condições ideais de segurança e proteção dos profissionais e adolescentes de forma ininterrupta (SÃO PAULO, 2013, p. 27). Participam diretamente da rotina diária dos adolescentes, acompanhando a higienização, alimentação, estudos, atividades de lazer e saídas do Centro para atendimentos externos e audiências judiciais.

Como requisitos para a ocupação desse cargo exigem-se ensino médio completo, altura mínima de 1,65m (homens) e 1,60m (mulheres), idade mínima de 25 anos, além da aprovação em concurso público. No rol dos conhecimentos específicos dessa avaliação, estão conhecimentos básicos acerca do ECA e do SINASE, além de documentos internos da instituição como os "CONCEITOS, DIRETRIZES E PROCEDIMENTOS" da Superintendência de Segurança e Disciplina da Fundação CASA-SP" (p.37, grifo do autor).

Com base nesses requisitos, depreende-se que se trata de uma função que tem como prioridade garantir a segurança e disciplina. Colocar-se nesse lugar pode se apresentar no campo prático como um desafio, haja vista as demandas suscitadas pelo espaço socioeducativo. Sofrimentos e adoecimentos engendrados a essa população se apresenta como possibilidades.

Em pesquisa realizada por enfermeiros com agentes socioeducativos de unidades de internação do Rio Grande do Sul, foi apontado a prevalência de distúrbios psíquicos nessa população resultante do estresse vivido no ambiente de trabalho (GRECO et al., 2015).

A depender das situações vividas no Centro de Atendimento, o sofrimento pode assumir o lugar de tensão e angústia, pela manutenção de um suposto controle em detrimento ao dos adolescentes, ou assumir o contorno da violência direta em razão das possíveis ameaças e embates vividos em confrontos ou situações de contenção (YOKOMISO, 2007).

Nesse sentido, os profissionais da pedagogia estão expostos a esse adoecimento, pois também estabelecem um contato direto e contínuo com os adolescentes, frequentemente vivenciando conflitos produzidos pelo espaço da privação de liberdade. Além disso, enquanto socioeducadores implicados em oportunizar os avanços pedagógicos dos adolescentes, deparam-se com sujeitos que frequentemente estavam fora do metiê escolar. São demandas que antecedem a 
privação de liberdade, mas que encontram nela palco para se manifestarem, seja pelo encontro ou desencontro.

A evasão escolar por vezes percebida na trajetória de vida dos adolescentes privados de liberdade nos remete ao fracasso das políticas públicas anteriores à socioeducação que pudessem garantir a proteção e o acesso à vida escolar dos adolescentes (BORBA et al., 2015).

A equipe da área de saúde, composta por técnicos de enfermagem e enfermeiros, também estão imersos nesses conflitos com o trabalho. São profissionais que constantemente são acessados pelos adolescentes que os buscam para sanar os diversos tipos de adoecimentos. As chamadas queixas, possibilitam ao adolescente a analgesia de suas dores e a oportunidade de uma escuta que possa significar sintomas físicos, conferindo um tom de singularidade diante de um processo institucional que tende a generalização. Sustentar esse lugar constantemente assediado pelos adolescentes pode se apresentar como um desafio ao profissional de saúde.

Na outra ponta, há a equipe compreendida como psicossocial formada por assistentes sociais e psicólogos. São responsáveis por acompanhar mais diretamente o adolescente e sua família. 0 contato com o adolescente ocorre, normalmente, por atendimentos individuais e em grupo, e com a família as abordagens são individuais, grupais, via telefone ou por meio de visitas domiciliares.

Apresentam conhecimento maior sobre a história de vida e do processo judicial do adolescente, por vezes, informações confidenciais e restritas ao restante da equipe. Prestam atendimentos individuais aos adolescentes de modo a compreender os significados do envolvimento infracional, servindo-se de ponte aos demais integrantes da equipe, rede e judiciário para que o adolescente possa ser compreendido para além do ato ilícito cometido e de seu comportamento no Centro. Articulam um trabalho com a rede de serviços da região de moradia do adolescente, sendo responsáveis pelo encaminhamento e acompanhamento durante a internação.

Frequentemente são acionados pelo judiciário a participarem de audiências e na produção de documentos, convocando-os a darem respostas sobre o andamento da Medida, bem como possíveis demandas psicopatológicas ou sobre prognósticos delitivos a que os adolescentes estariam impelidos a executar no futuro (YOKOMISO, 2018). 
As exigências de trabalho voltadas ao socioeducador, não somente aquelas oriundas da relação com os adolescentes, mas também as pertencentes a uma violência de ordem institucional, impregnada em suas estruturas e diretrizes, atravessam o socioeducador e abre precedentes para que alguns de seus profissionais façam uso das diversas expressões da violência e do exercício do poder como marco regulatório da disciplina e controle dos adolescentes e do próprio trabalho.

A seguir, aprofundaremos nas análises dos dados coletados no campo de pesquisa, ocasião que as relações de trabalho no contexto privativo de liberdade poderão ser discutidas à luz da prática desses profissionais.

\section{Análise dos Dados}

O questionário foi dividido em quatro blocos, construído a partir de temas mais gerais para os mais específicos conforme os objetivos desta pesquisa. Dentre os temas gerais, consideramos a contextualização do perfil do profissional e sua prática de trabalho como questões iniciais que serviram não apenas como aquecimento as demais perguntas, mas também para conhecermos o perfil dos socioeducadores.

Nessa mesma perspectiva, o segundo bloco de perguntas tratou dos conhecimentos que os profissionais têm em relação à política socioeducativa. Os demais blocos apontaram diretamente para o Princípio de brevidade e sua relação com a práxis exercida por esses profissionais. As questões dividiram-se entre dissertativas, alternativas e de relevância. Traremos maiores detalhes sobre o preenchimento dessas questões ao longo do texto.

\subsection{Contextualização do perfil profissional e a prática de trabalho}

Conforme trazido anteriormente, 20 participantes compuseram esta pesquisa. Apresentavam uma média de 15 anos de experiência de trabalho com a socioeducação, sendo a menor experiência de quatro e a maior de 30 anos. No que compete à questão de gênero destacamos que, do grupo pesquisado, cerca de $60 \%$ eram mulheres e 40\% homens (autodeclarados). Quanto à formação escolar/acadêmica dos socioeducadores pesquisados, nove apresentam Ensino Superior, cinco Pós-graduação, dois com formação técnica e quatro com o Ensino Médio Completo. 
Dentre as maiores dificuldades percebidas no trabalho, $55 \%$ apontaram questões relacionadas à instituição, 25\% ligadas a dificuldades no trabalho em equipe, $15 \%$ a impasses com a política socioeducativa e 5\% mencionaram problemas relacionados ao trabalho com os adolescentes.

Dos profissionais pesquisados, nove socioeducadores disseram ter formação ou orientação específica para o trabalho. Já os que relataram não ter formação específica somam 11 sujeitos, conforme Gráfico 2:

\section{GRÁFICO 2: FORMAÇÃO ESPECÍFICA PARA O TRABALHO}

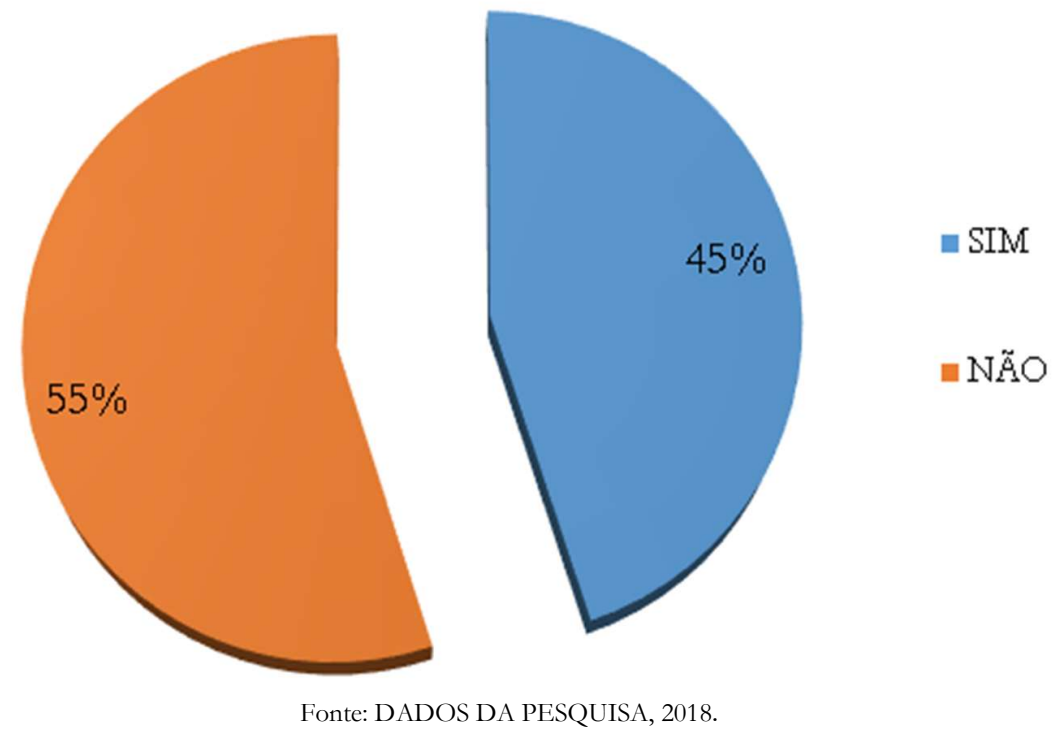

Os profissionais que possuem formação específica para o trabalho afirmaram que se tratou de uma busca pessoal em espaços alheios à instituição. Indicaram a ausência de orientação e formação dispensadas pela instituição que façam sentido com as demandas da prática, conforme podemos depreender no relato de W.J.: Nesses anos nunca vi de fato algum tipo de preparação adequada para tal trabalho. Aqueles que disseram ter recebido orientação da instituição vincularam esse conhecimento à cultura da transmissão oral ofertada por profissionais mais 
experientes em complemento as demais orientações recebidas, tal como dito por H.F.: Todas as informações que obtive vieram da Fundação e dos $A A S^{6}$ mais velhos.

Os sujeitos que assinalaram a ausência de formação específica para o trabalho socioeducativo relataram uma orientação inicial ao entrarem na instituição, mas que se mostrou incipiente diante das demandas do trabalho. Esses dados combinados com o item "formação" podem indicar a possibilidade de um distanciamento da instituição em relação a práxis desses trabalhadores. Em seus relatos trazem conteúdos que nos remetem a um desamparo institucional. Para esses profissionais, a presença da instituição na execução de seus trabalhos ocorre quase que exclusivamente como um agente fiscalizador, punitivo e ameaçador.

Quando perguntado como se sentiam em relação ao trabalho com adolescentes infratores, há um misto de respostas representadas por palavras como satisfação, utilidade, orgulho, vida, realização, produtividade, aprendizagem e missão, o que nos faz pensar que há a intenção e esperança de um trabalho diferenciado. Por outro lado, outras palavras surgiram como morte, fragilidade, desmotivação, impotência e vulnerabilidade, indicando a possibilidade de sofrimento advindo da prática profissional. Esse trecho nos remete a análise de Yokomiso (2007): "0 trabalho se torna apenas uma obrigação e instala-se o sentimento pela descrença em seu próprio ofício" (p.102).

Esse ponto também nos leva a pensar em um possível desgaste da identidade do socioeducador enquanto profissional implicado na garantia dos direitos humanos e na própria saúde desses profissionais: "A insatisfação no trabalho pode levar a consequências como absenteísmo, diminuição do rendimento, reclamações, tendo um efeito negativo sobre a saúde mental e física dos trabalhadores" (GRECO et al., 2015. p.99). Os reflexos negativos dessas consequências podem ser sentidos por toda cadeia socioeducativa do Centro: demais profissionais, as equipes de modo geral e os adolescentes. Nesses casos, a efetividade dos trabalhos pode ficar aquém de seus propósitos.

\subsection{Conhecimentos sobre a socioeducação.}

Esse bloco de perguntas buscou compreender o grau de conhecimento que os profissionais acreditam ter das leis que regem a política socioeducativa, bem como a conhecimento dos profissionais acerca do Princípio de brevidade. Essa questão está

\footnotetext{
6 Agente de Apoio Socioeducativo.
} 
ligada a uma autoavaliação dos socioeducadores em relação a seus conhecimentos sobre a temática.

Essa parte do questionário foi composta por perguntas fechadas, com cinco alternativas em que o número 1 poderia expressar o total desconhecimento e o 5 pleno conhecimento sobre o Estatuto da Criança e do Adolescente, sobre a Lei do SINASE e sobre o Princípio de brevidade. As respostas que ficaram entre esses números foram consideradas como medianas. Os resultados foram complementados com os relatos colhidos em nossos diálogos possibilitando, assim, o acesso ao aspecto qualitativo de suas opiniões.

No que se refere ao ECA, os dados mostram que os socioeducadores apresentaram um conhecimento que oscila entre o mediano e avançado. Já no item SINASE, os profissionais se dividiram em suas avaliações, quando $45 \%$ dos entrevistados disseram ter um conhecimento abaixo da média e $55 \%$ acima dela. No que compete o conhecimento sobre o Princípio de brevidade, os mesmos dados se repetiram.

Nos últimos dois quesitos - SINASE e Princípio de brevidade -, chamou-nos a atenção que a área da saúde e segurança relataram ter menor conhecimento. Esse ponto nos remete a maneira com que se organiza o trabalho dentro do Centro de internação: enquanto que a área psicossocial detém maiores informações sobre o processo do adolescente, mantém contato frequente com o judiciário e com a rede de serviços, além de uma produção constante de documentos, cabe as demais áreas, especialmente a de segurança, o trabalho mais "braçal". Os agentes de apoio socioeducativo são convocados a ocupar posições estratégicas para a garantia e manutenção da ordem e disciplina do Centro, apresentando-se como desafio marcar presença assídua nos espaços de discussão de caso.

\subsection{O Princípio de brevidade e a prática profissional}

Esse bloco de perguntas buscou compreender a relação do Princípio de brevidade nas práticas profissionais dos socioeducadores. Abarcou perguntas de alternativas e de relevância. Nas de alternativas o socioeducador pôde mensurar sua percepção em relação ao que foi inquirido, numa escala de 1 a 5 , em que a nota menor poderia expressar uma ocorrência menos frequente e a maior uma ocorrência muito frequente. As notas 2 e 3 foram consideradas medianas, ou seja, de frequência intermediária. Nas questões de relevância, foram considerados o grau de relevância em cada opção perguntada, numa escala de 1 a 5 , em que 1 foi considerado pouco relevante e 5 muito relevante. Esses resultados foram complementados com os 
relatos colhidos em nossos diálogos que exalaram a perspectiva qualitativa de suas opiniões.

A primeira referiu-se ao grau de importância dos fatores para a conclusão de uma Medida de Internação. Essa questão foi formulada pensando na relevância das metas estipuladas no PIA para a possibilidade de elaboração de um relatório conclusivo e os demais fatores que concorrem com esse quesito.

Quatro possíveis fatores de importância para a conclusão da Medida de internação foram apresentados. A elaboração desses fatores se baseou na literatura e na vivência empírica do pesquisador enquanto socioeducador ao perceber como alguns profissionais e o senso comum compreendiam a Medida Socioeducativa de Internação. Vejamos o Gráfico 3:

\section{GRÁFICO 3: FATORES DE IMPORTÂNCIA PARAA CONCLUSÃO DA MEDIDA DE INTERNAÇÃO}
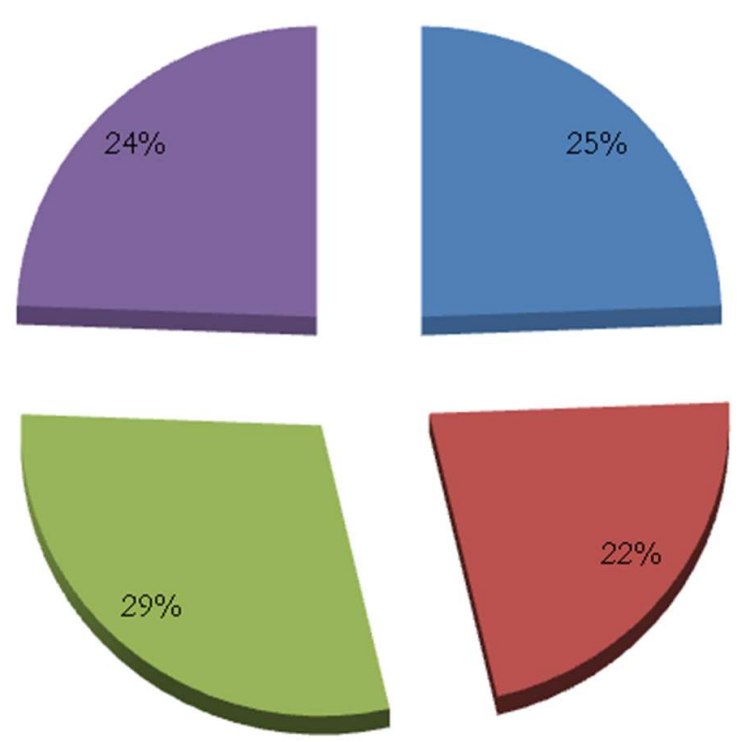

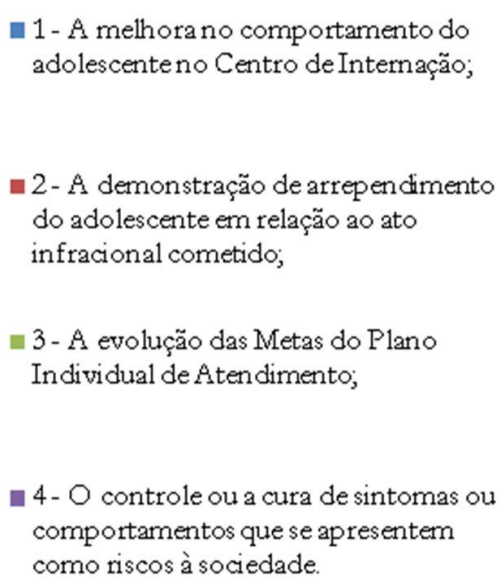

Fonte: DADOS DA PESQUISA, 2018.

Podemos depreender que os quatro itens apontados no Gráfico 3 concorrem com certa equivalência de importância. Chamou-nos a atenção a evolução das metas do 
PIA não ter ocupado lugar predominante, ao passo que sua observância pode reger a Medida Socioeducativa.

A demonstração de arrependimento pode estar imbuída nas metas do PIA e sua evolução pode ser considerada, por si só, possibilidade de retratação. No caso desta questão não há elementos suficientes para compreender ao que se referem os socioeducadores, mas há aqui um indício de que a demonstração de arrependimento é algo importante em suas avaliações. Resta-nos saber como essa demonstração deve ser feita e/ou validada pela equipe.

No que tange ao item 4, decidimos por incluí-lo em razão de uma lógica manicomial instalada em alguns procedimentos socioeducativos. Há adolescentes com demandas de saúde mental sendo encaminhados para a privação de liberdade sob a égide da proteção integral, ou mantidos na privação de liberdade claramente por essas demandas, quando na verdade esses sujeitos precisariam de acompanhamentos na rede de saúde extramuros.

O dado observado nesse quesito nos aponta como a ideia da cura ou controle de sintomas, tal como um manicômio, apresenta-se ainda com vigor na percepção dos socioeducadores a despeito das conquistas oriundas da luta antimanicomial, a qual buscou garantir direitos às pessoas com sofrimento mental usuárias de serviços de saúde. Anteriormente a esse movimento, o tratamento a essas pessoas baseava-se na lógica asilar em ambientes de superlotação e insalubres, permeados pela hipermedicalização e por violências físicas e psicológicas (VILLAS-BÔAS, 2015).

A melhora do comportamento do adolescente no Centro apresentou-se também como importante termômetro na avaliação dos socioeducadores para a conclusão dos casos. Esse item não aprofundou a complexidade desse tema, mas podemos depreender em nossa análise que a avaliação comportamental do adolescente privado de liberdade é um importante indicativo de sua evolução. Contudo, ao se conduzir por esse mérito corre-se o risco de desconsiderar a relação do viés punitivo, inerente a privação de liberdade, com o aspecto subjetivo do adolescente como possibilidades de engendramento de conflitos.

Esse quesito dialoga com a pergunta seguinte do questionário Qual influência das ocorrências no Centro para o prolongamento da Medida de Internação? Os resultados reafirmam a análise acima. Dos sujeitos pesquisados, 55\% consideraram muito relevante a influência das ocorrências para o prolongamento da Medida de internação contra 40\% que avaliaram essa influência como mediana. 
Sobre a compreensão dos socioeducadores quanto ao tempo de Medida, tratou-se de uma questão de relevância. Os dados apontam para a prevalência de opiniões que acreditaram que o tempo de internação é um importante agente para a promoção de mudanças. Vejamos no Gráfico 4:

\section{GRÁFICO 4: COMPREENSÃO DOS SOCIOEDUCADORES QUANTO AO TEMPO DE INTERNAÇÃO}

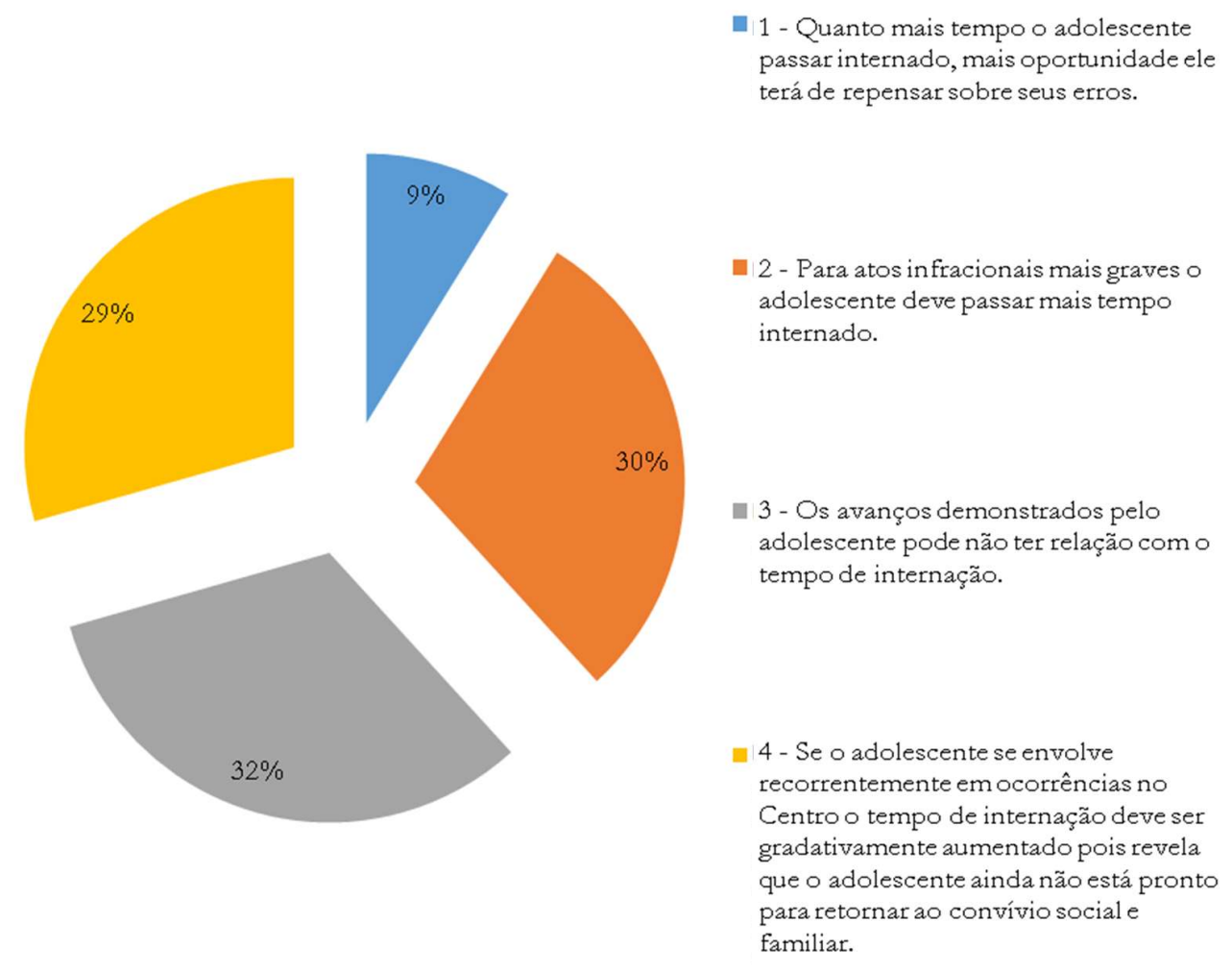

Fonte: DADOS DA PESQUISA, 2018.

Os dados apresentados no Gráfico 4 são respostas genéricas que não apontam para a especificidade de cada adolescente. No entanto, percebe-se nessa questão que o tempo de Medida desponta como importante elemento na condução dos trabalhos voltados aos adolescentes ao considerar a somatória das respostas dos itens 1, 2 e 4 .

Retomamos as indagações de Zapata (2010) quanto à eficiência das propostas pedagógicas em Medidas demasiadamente longas. Para a autora, Medidas extensas ou aplicadas a adolescentes reincidentes tendem a perder sua capacidade 
pedagógica por oferecer mais do mesmo. Vemos isso ocorrendo na prática quando adolescentes mais velhos de internação, na ocasião de escolha de cursos e oficinas, acabam tendo poucas opções que variem daquelas já cursadas anteriormente. No caso de reincidentes, há grandes possibilidades de voltarem a cursos já realizados em outra Medida. Nessas situações, para além da baixa variabilidade de aprendizado, o interesse dos adolescentes pelo estudo pode ficar comprometido.

É possível que se apresente como desafio à instituição sustentar uma variabilidade maior de cursos e oficinas aos adolescentes privados de liberdade por longa data ou reincidentes, no entanto, a ausência de alternativas que contemplem essas possibilidades empobrece o caráter socioeducativo colocando, inclusive, em xeque a eficiência do programa socioeducativo.

No que se referem às discussões da equipe sobre a brevidade da Medida, perguntamos se na elaboração do PIA é pensado um projeto de internação que busque sua execução no menor tempo possível. 25\% dos entrevistados disseram que não e 35\% afirmaram sua existência. Os demais 40\% relataram respostas que ficaram na zona mediana, apontamentos que indicam uma não ocorrência sistemática desses projetos nas elaborações dos PIA. Embora o número daqueles que apontem para a ausência desse projeto seja menor em relação os que indicam o contrário, sua soma com aqueles da zona mediana aponta para uma significativa parcela (65\%) de profissionais que consideraram que as discussões pouco privilegiam o tema da brevidade.

Esses dados apresentam relação com a pergunta seguinte do questionário: Com que frequência existe divergências de opiniões entre os profissionais da equipe quanto a conclusão de algum caso? Referimo-nos aqui as discussões de caso realizadas pelos socioeducadores que contemplam as Equipes de Referência, representada por profissionais da área da segurança, psicossocial, pedagogia e saúde.

Dos sujeitos entrevistados, cerca de 70\% consideraram a prevalência de divergências de opiniões ao se discutir a conclusão de caso, dados que indicam para uma significativa incidência de discordância entre os integrantes da Equipe de Referência. Havendo a necessidade de investigar suas razões, foram apontados aos socioeducadores cinco possíveis pontos de divergências, conforme descrito no Quadro 1: 
QUADRO 1: POSSÍVEIS PONTOS DE

DIVERGÊNCIAS ENTRE AS EQUIPES

\begin{tabular}{|c|c|}
\hline $1^{\circ}$ & Indisciplina do adolescente no Centro. \\
\hline $2^{\underline{0}}$ & Questões de ordem familiar. \\
\hline $3^{\circ}$ & $\begin{array}{c}\text { A necessidade de encaminhamentos técnicos que ainda } \\
\text { não foram realizados }\end{array}$ \\
\hline $4^{\circ}$ & Avanços insuficientes na área pedagógica. \\
\hline $5^{\circ}$ & $\begin{array}{c}\text { Insegurança de concluir o caso diante de uma futura avaliação do judiciário } \\
\text { quanto ao trabalho realizado. }\end{array}$ \\
\hline
\end{tabular}

Fonte: DADOS DA PESQUISA, 2018.

No que se refere ao primeiro ponto, $68 \%$ dos entrevistados apontaram que temas relacionados a indisciplina causada por adolescentes no Centro de Internação geram divergências na ocasião da reavaliação de Medida. Essa questão nos remete a uma possível "crise" existente entre os socioeducadores. Essa crise ocorre não somente em função dos distintos lugares ocupados pelos profissionais, mas também pelos diferentes pontos de vista acerca do adolescente (HERCULANO \& GONÇALVES,2011). Assim, dependendo do adolescente, principalmente aqueles ditos como mais "difíceis"7, as discussões para a reavaliação da Medida podem ter embates de opiniões, entre os que apóiam as prerrogativas da socioeducação e outros que fazem uso de métodos repressivos. Para o primeiro grupo, o envolvimento do adolescente em ocorrência ou situações de indisciplina pode ser fruto das adversidades da privação de liberdade, já para o outro, a ocorrência precisa ser punida com a permanência do adolescente na Medida de Internação. São perspectivas antagônicas que versam sobre o mesmo sujeito. Quem poderia apaziguar essa crise? Os autores indicam que a gestão tem papel fundamental nessa mediação, não no sentido de tendenciar para um lado ou para o outro, mas com o objetivo de promover diálogos e encontros.

No que diz respeito às questões de ordem familiar e demais encaminhamentos técnicos dispensados aos adolescentes, $62 \%$ apontaram que são pontos que causam divergências entre as equipes. Dois aspectos nos chamam a atenção nesse resultado. 0 possível prolongamento do tempo de internação motivado por encaminhamentos que ainda não foram realizados exprime a possibilidade das equipes não estarem se debruçando com celeridade sobre os casos. No que competem as questões de ordem familiar, a maioria das demandas extrapolam a Medida e precisam da rede para

\footnotetext{
${ }^{7}$ Expressão comumente utilizada ao se referir a adolescentes que se envolvem recorrentemente em ocorrência
} no Centro de Internação. 
atendimento. Mais do que a intervenção circunstancial da Medida, parte significativa das famílias precisa de acompanhamento desde antes e necessitam de suporte depois que a Medida findar. No entanto, por vezes a rede não se mostra eficiente nessa jornada, ou a família não se apresenta disponível as intervenções pensadas. Nesses casos caberá ao adolescente arcar com essa responsabilidade ficando mais tempo internado? Obviamente existem casos e casos, alguns inclusive com sérias violações de direitos que inviabilizam o retorno do adolescente para a família. Nossa preocupação é para as insistências demasiadamente longas em intervenções que se apresentam como pontuais.

Quanto aos avanços insuficientes na área da pedagogia, 26\% dos entrevistados apontaram que esse motivo gera divergências de opiniões da equipe. Que resultados esperamos de adolescentes que, em sua maioria, estavam fora do ambiente escolar em suas vidas pregressas à Medida de Internação? Que estratégias criativas e inovadoras foram pensadas ao longo da Medida para resgatar esses sujeitos e despertar neles o interesse pela vida escolar? Além da possibilidade de ser percebida com desinteresse, a escola dentro da privação de liberdade é oferecida de maneira compulsória aos adolescentes. Aqueles que não aderem a essa escolarização obrigatória e coercitiva, correm o risco de serem prejudicados nas reavaliações da Medida feitas pelos profissionais da Equipe e pelo judiciário (FRASSETO, 2016).

Por fim, 42\% consideram a insegurança de concluir o caso em razão das possíveis avaliações do judiciário quanto ao trabalho realizado pelos socioeducadores. Parecenos que há certo melindre dos socioeducadores em manter sua posição diante dos questionamentos do judiciário, principalmente quando eles divergem da normativa do encarceramento:

Se uma/um psicóloga/o entregar um relatório atribuindo o "hediondo" ato infracional de tráfico de drogas à escassez de oportunidades lícitas de geração de renda e ao cinismo da política proibicionista, o laudo tende a ser rejeitado ou devolvido, até que se reconheça tratar-se, na verdade, de uma insubmissão contumaz à autoridade dos pais, da lei e a uma indiferença ao danos sociais derivados do consumo de drogas. (FRASSETO, 2016, p.41)

O exemplo trazido pelo autor dialoga, inclusive, com as discussões sobre a supervalorização das ocorrências e situações de indisciplinas nas quais os adolescentes se envolvem no Centro. Essas manifestações, quando desprovidas de crítica e utilizadas de maneira superficial, reforçam a ideia do adolescente infrator e, portanto, trazem maus prognósticos para sua reinserção social. Nesses casos, nada como o "tempo" para resolver esses problemas. 
A relação dos socioeducadores com o judiciário parece-nos um tema pungente entre os socioeducadores entrevistados. Em nossos diálogos com os profissionais entrevistados inúmeras queixas surgiram quanto a um possível olhar de descrédito de seus trabalhos. Essa impressão é sintetizada no discurso de O.P..: hoje o Juiz pede ETJ até de jovens primários, sem grandes problemas de indisciplina por descrédito no trabalho realizado nos Centros. Essa relação será abordada com maior profundidade na análise a seguir.

\subsection{A brevidade da Medida e a relação com o judiciário}

Esse bloco de perguntas buscou contemplar a relação das equipes de referência na ocasião de envio de relatórios conclusivos ao judiciário. Essas questões, de maneira geral, foram avaliadas numa escala de 1 a 5 , em que a nota menor poderia expressar uma ocorrência pouco frequente e a maior uma ocorrência muito frequente. As notas 2 e 3 foram consideradas medianas, ou seja, de frequência intermediária. Esses resultados foram complementados com os relatos colhidos em nossos diálogos que exprimiram a perspectiva qualitativa de suas opiniões.

A primeira pergunta desse bloco foi a ocorrência de divergência entre a sugestão das equipes de referência com a decisão do judiciário acerca desse posicionamento. Dos profissionais pesquisados, $50 \%$ emitiram respostas na frequência intermediária, quando que as respostas que apontaram frequência maior foram de $38 \%$ e relacionadas a uma frequência de divergência menor $11 \%$, conforme Gráfico 5.

Pensamos que o maior índice permaneceu na zona intermediária por nem todos os socioeducadores terem o conhecimento mais aprofundado dos processos. Os integrantes da equipe de segurança, por exemplo, não conseguem manter frequência assídua nas discussões justamente pelas demandas que lhe são atribuídas, as quais se apresentam como prioridades em relação às demais atividades. Dentre essas funções que convocam o socioeducador, citamos o absenteísmo, circunstância que exige dos demais integrantes da equipe desdobramentos para ocupar as lacunas deixadas pelo profissional faltante.

A questão seguinte se referiu à divergência ocorrida entre a sugestão das Equipes de Referência com o posicionamento dos técnicos do judiciário. Há uma prevalência de respostas nas escalas "muito frequente" e de frequência intermediária, somando 44\% em cada escala. Em alguns casos, o juiz encaminha o adolescente para avaliação com sua equipe técnica do Fórum, composta por assistentes sociais e psicólogos. $\mathrm{Na}$ 
perspectiva dos socioeducadores, essa nova avaliação revela uma insegurança do judiciário diante das conclusões apontadas pelas equipes do Centro.
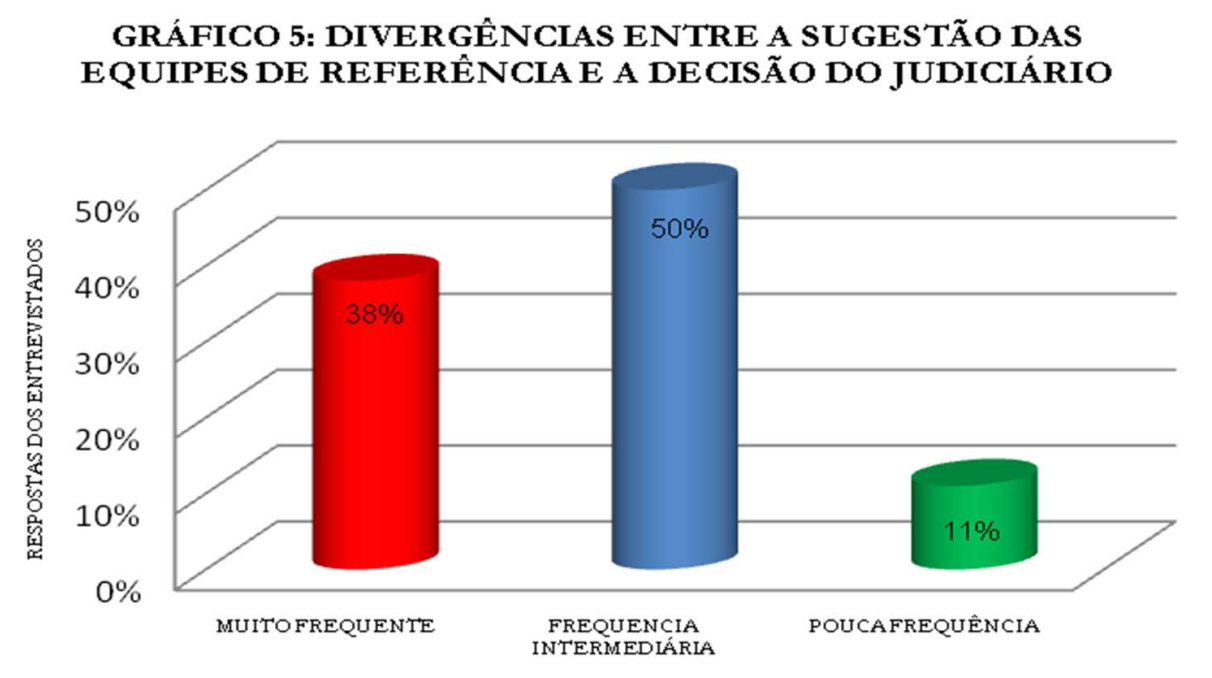

Fonte: DADOS DA PESQUISA, 2018.

Percebemos, nesse ponto, sentimentos de aviltamento do lugar ocupado pelo socioeducador, o qual pode ser visto com desconfiança pelos demais atores da rede. A despeito dos avanços percebidos na legislação e nas práticas de trabalho, o socioeducador carrega estigma de uma possível atuação marcada pelo modelo carcerário. Essa percepção é também alimentada por denúncias e notícias sobre violações de direitos ocorridas no âmago dos Centros de internação. Assim, os socioeducadores das Medidas de privação de liberdade, de maneira geral, podem ser vistos como potenciais violadores de direito. Recorre-se, então, a avaliações que transcendem o adolescente e que buscam aferir os socioeducadores.

A pergunta seguinte Em sua experiência você conhece casos de adolescentes que mesmo com a sugestão da Equipe de Referência para conclusão permaneceu internado por mais tempo mediante decisão judicial?. Dos entrevistados, 95\% afirmam a ocorrência de casos em que a Medida de internação é prolongada por decisão judicial mesmo com a sugestão da Equipe de Referência para a conclusão. Apesar das diversas argumentações técnicas apresentadas em relatório conclusivo, o judiciário tem mantido as internações. Essa questão buscou evidenciar a percepção dos socioeducadores quanto a essa problemática, no entanto, não se realizou 
pesquisa documental que pudesse confirmar os números exatos de manutenções realizadas.

Por fim, concluímos o questionário com uma pergunta que buscou compreender como os socioeducadores perceberam as manutenções de Medida na evolução dos casos dos adolescentes. Os resultados são apresentados no Gráfico 6:

\section{GRÁFICO 6: OPINIÃO DOS SOCIOEDUCADORES SOBRE A REPERCUSSÃO DAMANUTENÇÃO DA MEDIDA NA EVOLUÇÃO DOS CASOS DOS ADOLESCENTES}

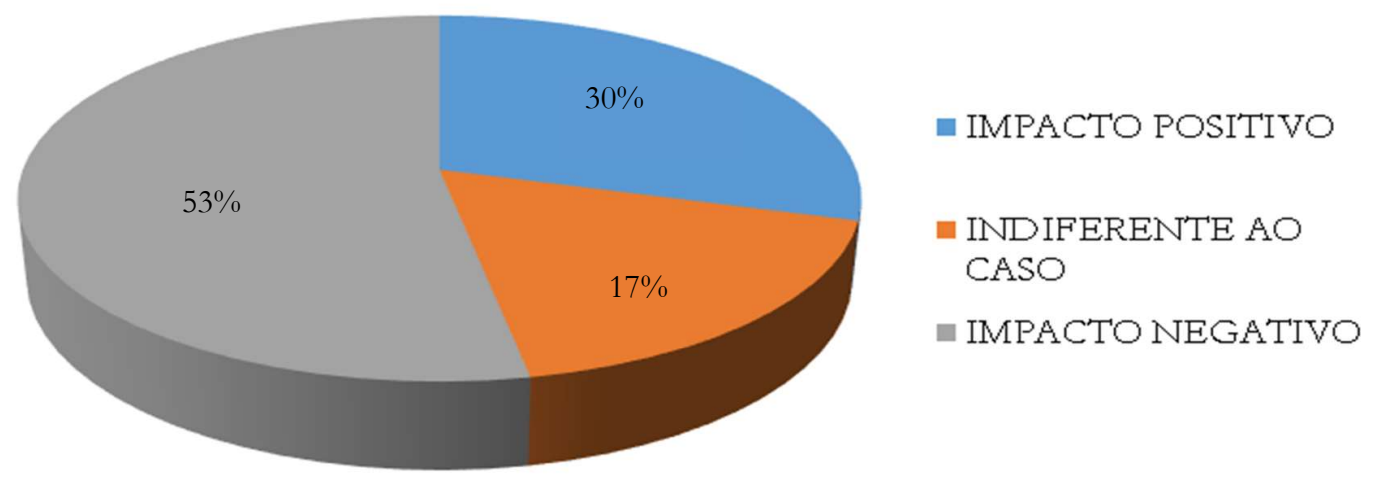

Fonte: DADOS DA PESQUISA, 2018.

Mais da metade dos profissionais pesquisados acreditam que a manutenção se apresentou de maneira negativa no desenvolvimento dos casos. Esses dados estão em consonância com o referencial teórico desta pesquisa, no qual o Princípio de brevidade é visto como elemento protetivo e seu avesso - prolongamento demasiado da Medida - se mostra como uma violação de direitos. É o que podemos compreender no relato de C.J.: As vezes, todas as possibilidades de crescimento na Medida já aconteceram e à partir daí pode correr um retrocesso nos avanços já alcançados.

Não obstante, há ainda aqueles que acreditam que a manutenção de Medida produza efeitos positivos, uma vez que se apresenta como uma resposta mais severa àqueles adolescentes considerados difíceis, os quais as Equipes não conseguem 
alcançar se não por meios coercitivos, é o que menciona O.P.P.: $O$ adolescente fica assustado com a manutenção da Medida, portanto, em geral se prontifica a atender as orientações da equipe de referência para ser liberado.

Chama-nos a atenção o percentual que considerou a manutenção da Medida como evento que repercutiu de maneira indiferente na evolução dos casos. Os estudos trazidos no referencial teórico desta pesquisa apontam para impactos negativos decorrentes da privação de liberdade em razão de seu viés punitivo. Por vezes, em um Centro de internação o termômetro com que se percebe o adolescente é quase que exclusivamente comportamental assim, qualquer outra manifestação que não ocorra por essa via pode ser despercebida. A compreensão de um relato de dor pode exigir confiança, vínculo, sensibilidade e empatia, acessos que somente canais significativos podem oportunizar.

\section{Considerações Finais}

Nossa compreensão com os resultados da pesquisa faz parte de um pequeno recorte dentro da socioeducação, por isso devem ser usados com parcimônia. Consideramos como necessário a investigação mais ampliada sobre o fenômeno do tempo da privação de liberdade, envolvendo socioeducadores de outros Centros. Para além desses sujeitos, pensamos na importância de compreender como o judiciário e os próprios adolescentes percebem a relação do tempo dispensada à Medida, envolvendo-os, também, como sujeitos de pesquisa.

Acerca de nossas percepções sobre a pesquisa atual, no que tange o tempo cronológico da Medida, depreende-se que ele é uma variável considerada importante para os socioeducadores e utilizada como método de intervenção. Embora não haja fixação a priori desse tempo, ou de seu prolongamento, ele é compreendido como agente que pode provocar mudanças no adolescente a despeito das demais intervenções. No fracasso das ações técnicas, pedagógicas e disciplinares, o tempo surge como uma espécie de salvaguarda para os profissionais.

Na avaliação dos socioeducadores, o prolongamento da Medida também é uma variável considerada pelo judiciário apesar da evolução das metas do PIA, das intervenções socioeducativas realizadas, os limites do sujeito e da Medida apontados pelos profissionais. Embora a maioria dos socioeducadores considere o prolongamento do tempo de internação em suas próprias avaliações, quando essa manutenção é fruto de decisão judicial, parte considerável dos socioeducadores pesquisados a percebem como danosa na evolução dos casos. Além disso, as 
manutenções de Medida promovidas pelo judiciário em casos que as equipes do Centro sugerem o retorno ao convívio social são percebidas como ações de aviltamento do lugar do socioeducador.

No que se refere às queixas dos socioeducadores manifestas ao longo da pesquisa, suas maiores dificuldades são com a instituição, seguida de problemas com a própria equipe. A formação continuada também se mostrou como uma importante queixa. Parte significativa dos profissionais considerou ter poucos conhecimentos sobre o ECA e SINASE. Trata-se de conhecimentos específicos que a graduação pode não abarcar, por isso mostra-se necessário a organização de cursos que façam a ponte entre a legislação, teoria e a prática.

Relatam tentativas da instituição em oferecer formação continuada na modalidade on-line, mas ela é considerada distante das demandas dos socioeducadores e, principalmente, não contemplam os encontros presenciais tão caros que os profissionais necessitam. Para sujeitos que se sentem desamparados pela instituição, formações a distância somente reforçam a ideia de isolamento profissional. A ausência da instituição nesse campo possibilita que outras maneiras de trabalho vinguem no contexto socioeducativo, algumas marcadas por métodos criativos de acesso e cuidado dos adolescentes, já outras amparadas em métodos punitivos de controle dos adolescentes. É imprescindível que a instituição regule esses saberes, não para restringir a espontaneidade dos profissionais que se dedicam a construir encontros significativos com os adolescentes, mas para coibir a multiplicação de práticas violadoras de direitos, orientando esses profissionais a adotarem outras posturas.

Consideramos importante a elaboração de ações que possam resgatar a autoestima do socioeducador, desconstruindo os possíveis estigmas que circulam no imaginário social. A ideia de que os socioeducadores são violadores de direitos em potencial é herança de uma tradição carcerária e fruto também de recorrentes situações de violência perpetradas contra os adolescentes. A observância das leis deve ser seguida, mas a instituição não pode se mover somente por essa esteira, fazendo uso de métodos de ameaça e punição como controle da violência. Esse movimento cria cenários de desamparo, nos quais o uso da violência pode se apresentar como possibilidade de sobrevivência. Violência pode gerar violência. Ameaça pode gerar ameaça. É imprescindível a promoção de encontros significativos e de cuidado. Somente eles podem provocar mudanças significativas. 


\section{Referências}

BRASIL. Levantamento anual SINASE 2016. Brasília: Ministério dos Direitos Humanos, 2018. Disponível em: http://www.sejudh.mt.gov.br/documents/412021/ 9910142/Levantamento+SINASE+_2016Final.pdf/4fd4bcd0-7966-063b-05f538e14cf3 9a41. Acesso em: 03 de Mar. 2018.

BRASIL. Lei 12.594 - Sistema Nacional de Atendimento Socioeducativo (SINASE), de 18 de Janeiro de 2012a. Disponível em: http://www.planalto.gov.br/ccivil_ 03/_ato2011-2014/2012/lei/l12594.htm. Acesso em: 03 de Jun. 2018.

BRASIL. Senado Federal. Proposta de Emenda à Constituição n. 33, de 03 de Julho de 2012b. Disponível em: https://www25.senado.leg.br/web/atividade/materias//materia/106330. Acesso em 03 de Jun. 2018.

BORBA, Patrícia Leme de Oliveira; LOPES, Roseli Esquerdo.; MALFITANO, Ana Paula Serrata. Trajetórias escolares de adolescentes em conflito com a lei: subsídios para repensar políticas educacionais Ensaio: Avaliação e Políticas Públicas em Educação. Rio de Janeiro, 23 (89), 937-963, 2015. Disponível em: http://www.scielo.br/pdf/ensaio/v23n89/1809-4465-ensaio-23-89-0937.pdf. Acesso em: 03 de Jul. 2018.

FRASSETO, Flávio Américo. Processo de avaliação psicológica e a produção de laudos. In.: CONSELHO REGIONAL DE PSICOLOGIA DE SÃO PAULO. Caderno de Debates: Visitas institucionais à Fundação Casa São Paulo. Conselho Regional de Psicologia de São Paulo. São Paulo: CRP SP, 2016. p.40-45.

GOFFMAN, Erving. Manicômios, prisões e conventos.São Paulo: Perspectiva, 1974.

GRECO, Patricia Bitencourt Toscani; MAGNAGO, Tânia Solange Bosi de Souza; LUZ, Emanuelli Mancio Ferreira; URBANETTO, Janete de Souza, PROCHNOW, Andrea. Prevalência de distúrbios psíquicos menores em agentes socioeducadores do Rio Grande do Sul. Revista Brasileira de Enfermagem: Brasília, 68 (1), 93-101, 2015. Disponível em: http://www.scielo.br/pdf/reben/v68n1/0034-7167-reben-68-010093.pdf. Acesso em: 03 de Jun. 2018.

HERCULANO, José Antônio Haas; GONÇALVES, Marcelo Gomazzi. Educador social: segurança e socioeducador, a conciliação. Serviço Social em Revista. Londrina, 14
(1),
74-101,
2011.
Disponível
em: 
www.uel.br/revistas/uel/index.php/ssrevista/article/ download/1 0674/10889. Acesso em:08 de Jul. 2018.

LIMA, Janice Raquel; PEREIRA, Jussivania Carvalho Vieira Batista; BARROS, Solange Maria. Práticas discursivas de Agentes socioeducadores: Uma análise crítica do discurso. Revista Humanidades e Inovação. Palmas, 5 (1), 175-185, 2018. Disponível em: https://revista.unitins.br/index.php/humanidadeseinovacao/article/view /574. Acesso em:25 de Mai. 2018.

MELGAÇO, Paulo; ALMEIDA, Bruna R. O Plano Individual de Atendimento (PIA) nas Medidas Socioeducativas: para o adolescente, com o adolescente ou sobre o adolescente? IN: 0 Estatuto da Criança e do Adolescente: refletindo sobre sujeitos, direitos e responsabilidades. Brasília: Conselho Federal de Psicologia, 2016. p.198207.

MINAS GERAIS. Comentários à no Lei 12.594/2012. Jurídico: Revista do Ministério Público do Estado de Minas Gerais. Edição SINASE. Belo Horizonte, 2014. Disponível em:

http://www.crianca.mppr.mp.br/arquivos/File/publi/sinase/comentarios_sinase_ mp mg_2014.pdf. Acesso em:03 de Jul. 2018.

OLIVEIRA, Magda Martins. Processo socioeducativo. In.: LAZZAROTTO, Gislei Domingas Romanzini [et al.]. Medida Socioeducativa: entre A \& Z. Porto Alegre: UFRGS/ Evangraf, 2014. p.199-200.

SÃO PAULO. Boletim Estatístico Semanal 18.05.2018. Fundação Centro de Atendimento Socioeducativo ao Adolescente - Fundação CASA. 2018. Disponível em: http://fundacaocasa.sp.gov.br/up.ashx?f=boletins/Boletim2/046.\%20Boletim\%20 Presid\%C3\%AAncia\%2018.05.2018_v1.xlsx\&t=file. Acesso em: 19 de Mai. 2018.

SÃO PAULO. Edital 001/2013 de abertura de inscrições. Fundação CASA-SP Centro de Atendimento Socioeducativo ao Adolescente Concurso Público № 001/2013. São Paulo: Secretaria de Estado da Justiça e da Defesa da Cidadania, 2013. Disponível em: http://www.fundacaocasa.sp.gov.br/View.aspx?title=concu rso-2013\&d=2093. Acesso em 23 de Abr. 2018.

SARAIVA, João Batista Costa. Brevidade In.: LAZZAROTTO, Gislei Domingas Romanzini [et al.]. Medida Socioeducativa: entre A \& Z. Porto Alegre: UFRGS/ Evangraf, 2014. p.47-49. 
VICENTIN, Maria Cristina Gonçalves. Saúde mental no contexto de privação da liberdade. In.: CONSELHO REGIONAL DE PSICOLOGIA DE SÃO PAULO. Caderno de Debates: Visitas institucionais à Fundação Casa São Paulo. Conselho Regional de Psicologia de São Paulo. São Paulo: CRP SP, 2016.p.24-29.

VILLAS-BÔAS, Patrícia. A luta antimanicomial e a política pública em saúde mental. Pathos: Revista Brasileira de Práticas Públicas e Psicopatologia. São Paulo, 1 (2), 03 08, 2015. Disponível em: http://joom.ag/hmSp/p4. Acesso em 24 de Abril de 2018.

YOKOMISO, Celso Takashi. Violência e descontinuidade psíquica: um estudo sobre a Fundação CASA . Dissertação de Mestrado. Programa de Psicologia Social, Instituto de Psicologia, Universidade de São Paulo, São Paulo, 2007. 266p. Disponível em:http://www.teses.usp.br/teses/disponiveis/47/47134/tde-15012008-

155933/pt-br. php. Acesso em 13 de Fev. 2018.

YOKOMISO, Celso Takashi. Psicoterapia e medidas socioeducativas de internação: armadilhas e desafios. Pathos: Revista Brasileira de Práticas Públicas e Psicopatologia. São Paulo, 7 (4), 07-14,2018. Disponível em: http://joom.ag/zwjY/p8. Acesso em 06 de Julho de 2018.

ZAPATA, Fabiana Botelho. Medida socioeducativa de internação: um estudo a respeito do tempo de privação de liberdade associado à repetição do ato infracional. Dissertação de Mestrado. Programa Mestrado Profissional Adolescente em Conflito com a Lei, UNIBAN, São Paulo, 2010.110p. Disponível em: https://s3.amazonaws.com/pgsskroton-

dissertacoes/d88819aebafc0306ad30b6985b92 c435.pdf. Acesso em: 12 de Mar. 2018.

Recebido em 07/08/2018

Aprovado em 08/09/2018 